\title{
Interdisciplinary Planning and Scientific Support to Rehabilitate and Preserve the Values of the Holy Aedicule of the Holy Sepulchre in Interrelation with Social Accessibility
}

\author{
Antonia Moropoulou*, Calliope Maria Farmakidi, Kyriakos Lampropoulos, Maria Apostolopoulou
}

School of Chemical Engineering, National Technical University of Athens, Greece

Copyright $\mathrm{O} 2018$ by authors, all rights reserved. Authors agree that this article remains permanently open access under the terms of the Creative Commons Attribution License 4.0 International License

\begin{abstract}
The need for the immediate rehabilitation of the Holy Aedicule of the Holy Sepulchre involved the collaborative efforts done by the religious communities, scientific experts, and policy makers with the aim to secure the structural integrity and sustainable rehabilitation of the monument, which stands as a par excellence landmark of spiritual renewal and worshiping for the generations to come. Using best practices and integrating specific disciplinary expertise knowledge, the rehabilitation project has been throughout relevant and extrovert to the society, engaging the public in order to share problematic as well as scientific findings, to understand and promote its cultural resources. In order to achieve this, an innovative scientific method was developed by the National Technical University of Athens Interdisciplinary Team involving methods and perspectives from different disciplines, namely, from the scientific fields of architecture, civil engineering, surveying engineering, materials science and engineering, information technology, archaeometry and archaeology in dialogue with the religious communities. Reference is made to the cultural policy, highlighting the benefit of the interaction between ideas, institutions, and the common interest for the protection of monuments. The aforementioned, along with the organization programming, the integrated governance of the project, based on management functions, such as planning, budgeting, fundraising, evaluation and quality control, designed a prolific interdisciplinary agenda. This paper presents practical and theoretical work in heritage protection management, communicates the tools involved in master scientific issues, while it seeks to engage the interest of the public in order to interact actively, participate in its protection and add constructively on its future life.
\end{abstract}

Keywords Holy Sepulchre, Rehabilitation,
Interdisciplinary Planning and Cultural Policy, Preservation of Values, Social Accessibility, Community Archaeology

\section{Introduction}

The Holy Sepulchre complex at Calvary, in Jerusalem, embodies the two holiest sites of Christianity. The site where Christ was crucified and the monument acknowledged as the Holy Tomb, where he was buried and resurrected. The initial rock - cut grave, at a later date, was covered by a ciborium supported by pillars and then, enclosed in a mausoleum-type building. This freestanding domed ciborium-like structure, standing over the spot of the burial, is the Aedicule of the Holy Sepulchre. Designed in the form of a small building, as a shrine, it marks a holy place of worship. The Aedicule is located within another building, the Church of Resurrection, which was constructed in Jerusalem in AD 326, in the Constantinean era. Over the centuries, the Holy Aedicule expanded and altered in form, and has undergone many construction and restoration phases throughout its history. Following a destructive fire, in 1810, the latest restoration program was undertaken by the Architect "Kalfa" Komnenos [1-6].

Within the following two centuries, however, the Aedicule sustained significant damage and deformations that needed to be addressed in order to ensure the structural integrity and sustainable preservation of this unique historical and cultural monument. An interdisciplinary study was conducted by the NTUA team for the Protection of Monuments (Prof. A. Moropoulou, Prof. E. Korres, Prof. A. Georgopoulos, Prof. C. Spyrakos), after the invitation by His Beatitude, Theophilos III, Patriarch of Jerusalem, to diagnose the prevailing decay factors and to assess the state 
of preservation of the Aedicule. The NTUA in 2015 signed a program agreement with the Greek-Orthodox Patriarchate of Jerusalem and implemented an "Integrated Diagnostic Research Project and Strategic Planning for Materials, Interventions Conservation and Rehabilitation of the Holy Aedicule of the Church of the Holy Sepulchre in Jerusalem" [7,8]. According to the results achieved, appropriate and compatible restoration and conservation materials and interventions were proposed and planned.
Based on the findings and proposals of this research project, a historic Common Agreement (Figure 1) was signed among the three leaders of the Christian Communities Guardians of the Holy Tomb - for the implementation of the project regarding the "Conservation, reinforcement and repair interventions for the rehabilitation of the Holy Aedicule", entrusted to the Chief Scientific Supervisor, Prof. A. Moropoulou [9-11].

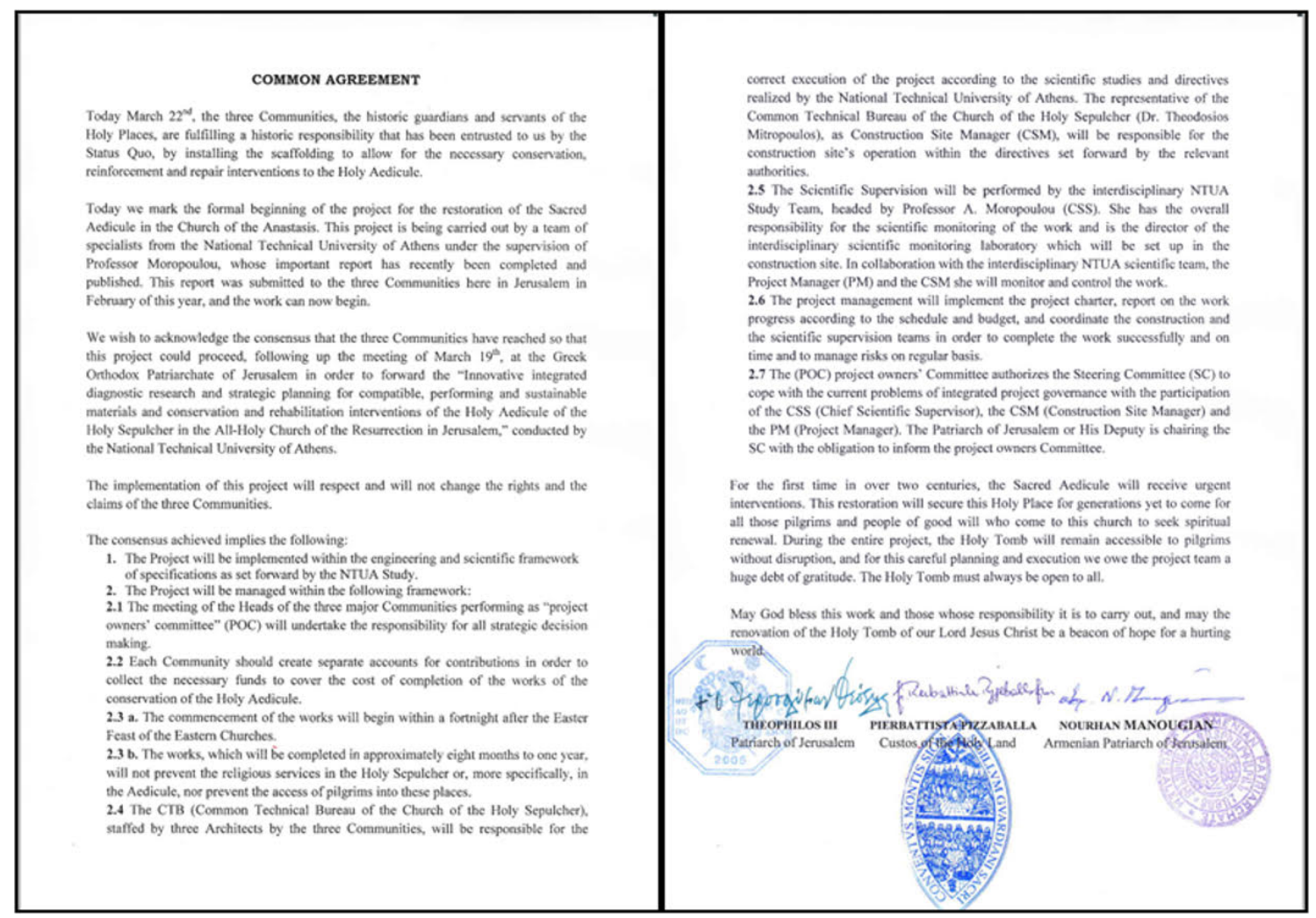

Figure 1. Common agreement of the Leaders of the three Christian communities- guardians of the Holy Tomb

\section{Review of the Methods and Proposals Applied by the Diagnostic Study Aiming to Sustainably Preserve the Holy Aedicule for Pilgrimage Worshiping}

An integrated diagnostic study evaluated the Aedicule's current state of preservation, thus, the necessity of a rehabilitation project was proven and compatibility and performance specifications of the materials and interventions required for the Aedicule's rehabilitation were set to reinstate its structural integrity and improve its dynamic behavior, aiming towards sustainable preservation, while providing social accessibility and ensuring the preservation of the Holy Tomb's values. The latter in terms of values were at the core of the common agreement, as the final purpose was to give back to the pilgrims and further than that to the world, not only a monument of Christianity but 'a church for spiritual renewal' with emphasis in the notion of revival through 'resurrection' whether spiritual or religious. More specifically the intention to preserve the monument for the future generations falls within the realms of sustainable development in the global context. The importance of such a concept lies at the center of the current social and international demand to seek through cultural heritage the points that unite us rather than the issues that divide us. Therefore the need for the intervention through restoration in cultural monuments that represent the highest values of humanity in such turbulent times is becoming even more demanding. Nothing of the sort though could ever become possible without the use of innovative technologies and international collaboration. These two factors secure the physical existence and the notional importance of the monument, since people from all backgrounds are coming together in terms not only of a scientific or religious in character project, but rather in a common agreement of an international society. This concept lies behind the line of interventions that are to be described in the following sections. 
An innovative diagnostic study of the non-visible layers of the Aedicule, documented the whole structure, identified the construction layers, the prevailing decay problems and described the necessary compatible and performing materials and interventions [7]. For this purpose, methods from various disciplines were implemented, with emphasis on non-destructive techniques. The use of ground penetrating radar (GPR) prospection of the structure, along with the architectural analysis, revealed the previous construction phases of the Aedicule, as well as the remnants of the Holy Rock (Prof. A. Moropoulou, leading the research team of the NTUA School of Chemical Engineering, and Prof. M. Korres, leading the research team of the NTUA School of Architecture) [12, 13]. Infrared Thermography (IRT) indicated a highly anisotropic heat distribution over the structure, attributed to the presence of incompatible materials within the structure, resulting in a significant local thermal heterogeneity. Stones and mortars were examined with various analytical techniques (XRD, TG/DTA, FTIR etc.) [7, 8, 14, 15]. Masonry core samples were taken, in order to undergo materials characterization to determine the mechanical and physicochemical properties of the building materials sampled $[8,14]$. The study indicated that the observed buckling at the lower parts of the Aedicule is mainly attributed to the swelling of the masonry at its lower level and the degradation of mortars. A historic cause of the swelling was the water precipitation through the open oculus of the dome above the Aedicule, until 1870. Thereafter, as investigated by the NTUA Team (Chief Scientific Supervisor, Prof. A. Moropoulou, and the NTUA interdisciplinary team), the main source of humidity is the uptake through capillary rise from the rainwater drainage and problems in the sewage system in the underground area.

An integrated geometric survey was conducted using two approaches. The first approach consisted in analysing and processing digital images obtained by a high resolution camera in order to create a three-dimensional model of the Holy Aedicule, which included texture of the external surfaces and was georeferenced to a local network (Prof. A. Georgopoulos, leading the research team of the NTUA School of Rural and Surveying Engineering) [16]. The above study results were coupled in order to achieve an integrated proposal. The 3D model, in combination with the revealed internal layering of the Aedicule $[12,13]$ and the materials' properties, were utilized for the optimization of numerical models of the Aedicule, to assess its dynamic behavior and to identified critical areas of vulnerability (Prof. C. Spyrakos, leading the research team of the NTUA School of Civil Engineering) [7, 11].

\section{Findings during the Implementation of the Rehabilitation Project, Revealing Values}

The implementation of the project followed a strict 9-month period procedure (Figure 2). Before the initiation of the works final implementation studies regarding all rehabilitation issues were presented and accepted by the Project Owners' Committee (POC), thus enabling the equipment and materials procurement.

A major unique prerequisite of the project set by the Project Owners' Committee was the organization of a worksite without disrupting any religious functions or the flow of pilgrims. This required a setup that preserved the rotunda floor, enabled the continuous access to the Aedicule chambers and fulfilled safety requirements. In a historic decision, the three Christian communities provided space within the Church equally, in order to host the Conservation Laboratory (part of the Latin Gallery), the Interdisciplinary Laboratory (rooms around the ground Rotunda area) and materials and heavy equipment storage area (Arches of Virgin area).
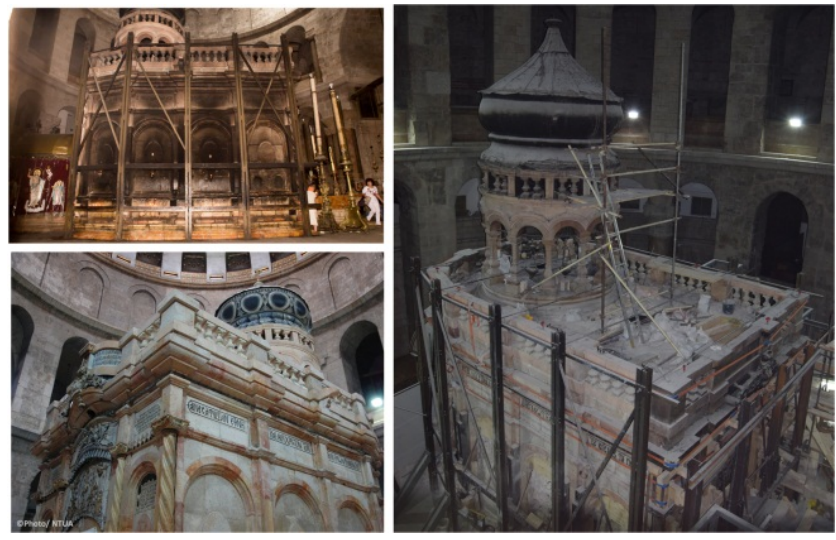

Figure 2. The Holy Aedicule before (upper left), during (right) and after (lower left) the rehabilitation project

First the marble panels, comprising the exterior façade were disassembled and the slabs were removed. Each stone slab was coded, documented and transferred to the Latin Gallery in order to undergo cleaning and protection interventions. Behind the slabs, the disintegrated Komnenos filling mortar was removed. The inner masonry of the structure was revealed and the joints were cleaned. A compatible and performing restoration mortar was applied to repoint the masonry, as selected in the study.

The strengthening of the structure was conducted in accordance to the diagnostic study proposals, continuously updated and optimized by the NTUA Team due to critical findings (in the internal layers) that emerged during the rehabilitation project and after the removal of the stone slabs.

Poorly constructed or greatly deteriorated parts of the masonry, which posed a risk to the structural integrity of the structure and the preservation of the Holy Rock, were repaired or reconstructed, with compatible stones and mortars, where needed. The repair masonry comprised of orthogonal stone blocks - quarried locally in Jerusalem and of the same type of original materials - with largely standardized dimensions and built in a manner as to follow 
the form of the remnants of the original monolithic Aedicule, relieving the original material of vertical structural stresses, thus 'embracing and protecting' the Holy Rock.

After the repointing and reconstruction of the masonry, the columns were reset prior to the completion of the remaining strengthening measures, gradually reinstating the original geometry of the Holy Aedicule. The gradual reduction of deviations from verticality during the works was verified.

Geometric and architectural documentation data facilitated grout injection tube design and documentation. Installation of injections pipes, created a matrix at different depths, based on sections of the geometric model.

As initially proposed in the diagnostic study, the grouting of the masonry was performed. Interconnecting actions were suggested by NTUA Team, approved by POC and implemented in order to facilitate the grouting process and ensure its effectiveness. One of the major concerns related to potential leakage of the grout material within the structure and towards the underground environment.

Regarding the Aedicule, the major concern related to the potential leakage of grout material in the interior of the Holy Tomb. With the internal configuration of the Tomb still undetermined at that stage, it was not clear whether a space of significant volume existed between the marble plate of the Tomb and the actual burial rock surface that could potentially be filled with grout material.

NTUA Team justified the necessity and specified the process of opening the Tomb without damaging any of the marble facings of the Tomb, which was approved by the $\mathrm{POC}$, in a historic decision.

In the same framework, in order to control the grout process, facilitate evaporation and removal of moisture from the Holy Rock, and monitor the evolution of the humidity content of the rock material within the masonry around the Tomb Chamber, it was proposed by the NTUA team and approved by the POC, that part of the interior marble facings of the Tomb Chamber opposite the Holy Tomb was removed, so that the Rock material was visible and accessible during the grouting process. The Tomb opened on October $26^{\text {th }} 2016$ (Figure 3), and remained open for sixty hours, during which the grouting of the structure was completed, providing the opportunity to perform, for the first time ever, documentation of the burial surface and characterization of the materials within the Holy Tomb. The Media acted as a catalyst to disseminate the values of the monument, spanning a range of cultural and educational perspectives and furthermore offered new insights into the project.

In addition to the necessity relating to the grouting process, the POC, after suggestion of the NTUA team, decided that the opening remain after the conclusion of the works, in the form of a Holy Rock observation window (Figure 4), to provide pilgrims with a view of the original rock material - remnants of the original monolithic Aedicule - as well as highlight the value of the preservation of the Holy Rock and the importance of the rehabilitation of the realized works.

Regarding the exterior environment of the Aedicule, the major concern related to the potential leakage of grout material through voids and openings around and below the Aedicule. To this end, comprehensive underground survey was performed using Ground Penetrating Radar and Electric Resistance Tomography, in order to identify and map voids and natural and man-made underground features. In this framework, Athens Water Supply and Sewage Company assisted NTUA Team with specialized robotic cameras in mapping the location and assessing the state of preservation of underground water and sewage pipes. Furthermore, the NTUA team conducted a geometric survey of two underground spaces at the north and south of the Holy Aedicule, which were in contact with the structure and potentially could serve as grout leakage paths.

Assessment of the effectiveness of the grouting materials and procedure by advanced NDT and analysis of grout volume distribution showed that both homogenization of the structural layers and consolidation of the Holy Rock were achieved by the injection of compatible grouts.

Following the grouting process the remaining stages of the strengthening of the structure were carried out. The reset columns were anchored to the main masonry with titanium anchors and joints and secured with a compatible and performing restoration mortar. An additional titanium mesh was added onto the strengthened masonry, to 'homogenize' the 'concrete' layer that was added thereafter. The exterior stone slabs, after their cleaning and protection interventions, were then assembled in their respective position. They were secured into position and anchored to the masonry by a carefully designed matrix of vertical, horizontal and corner anchors and interconnection pins. After the reassembly of the slabs, per height zone all around the Aedicule facades, a compatible and performing restoration mortar was added in the layer between the external stone slabs and the reinforced masonry. The process was repeated per zone, until all the façade panels were completed.

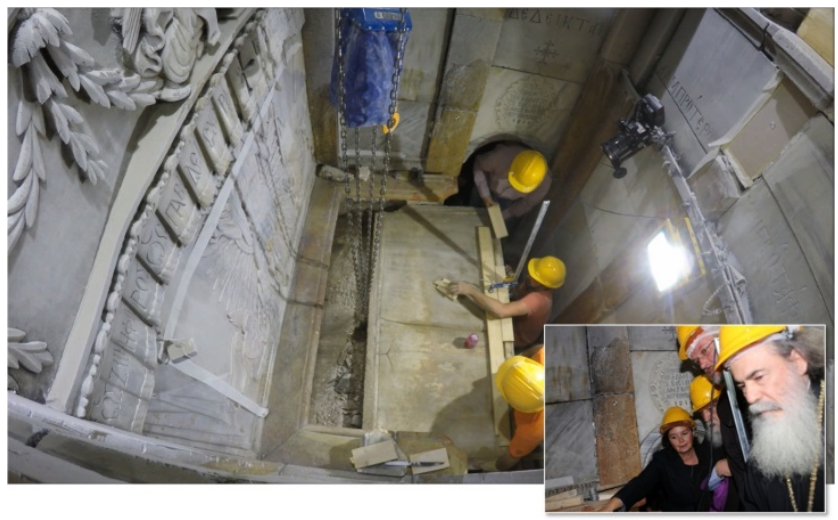

Figure 3. The opening of the Tomb of Christ after five centuries with the permission of the three Christian Communities "The Tomb of Christ is alive" 
Komnenos' restoration signature was found by the masons during the works at the southeastern corner of the Holy Aedicule (Figure 5).

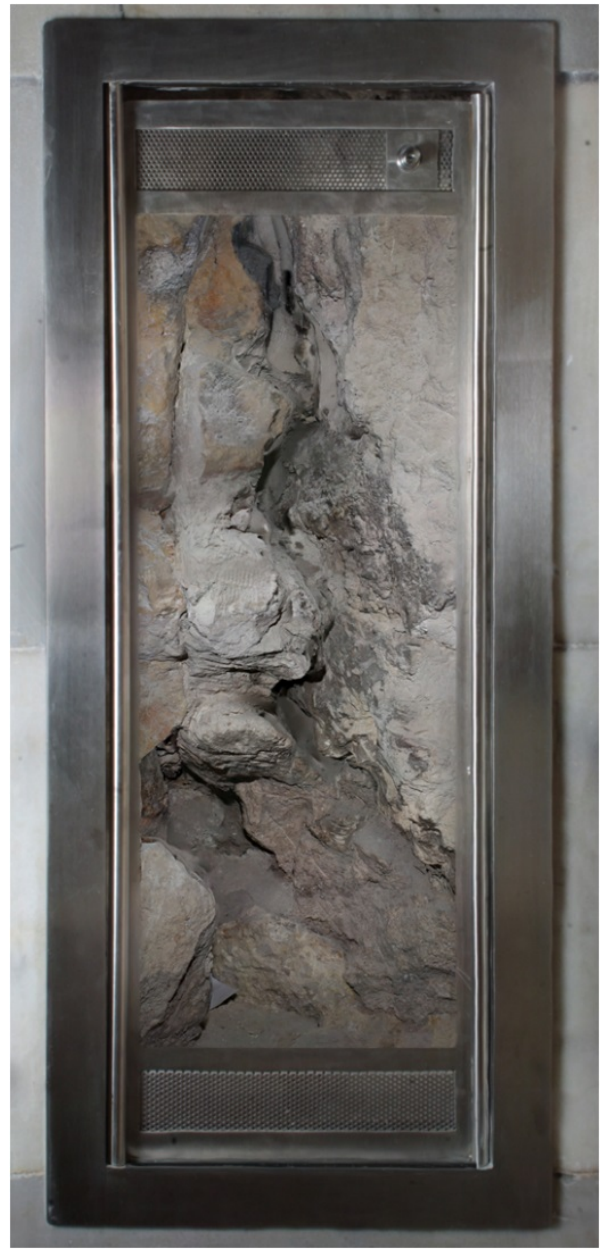

Figure 4. The Holy Rock became visible to the pilgrims after consolidation

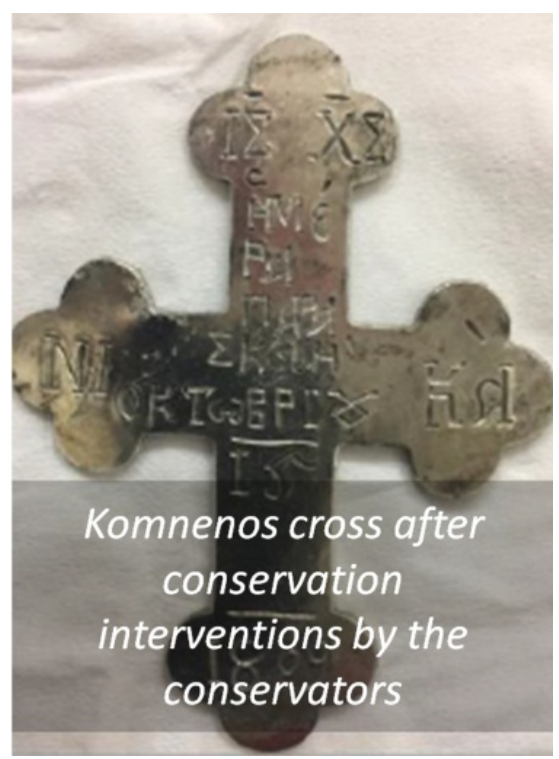

Figure 5. Komnenos' restoration: the Cross signature found by the masons during the works at the SE cornerstone of the Holy Aedicule
Following reassembly of the façade panels, the in situ cleaning and protection of the exterior surfaces of the Aedicule were completed. In parallel throughout the works, cleaning and protection of decorations and surfaces were carried out in other interior areas, such as the Chapel of the Angel and the interior dome above the Tomb Chamber, along with the Greek inscriptions (Figure 2 lower left). The conservation of hidden frescoes at the Chamber of the Tomb revealed the story and symbolism of the Myrrhbearers (Figure 6) [17]. The Myrrhbearers approached the Funerary Tomb to pay their respect through incenses, but were the first to be delivered the message of the Alive Tomb and now pay their respect through their eternal testimony of Resurrection.

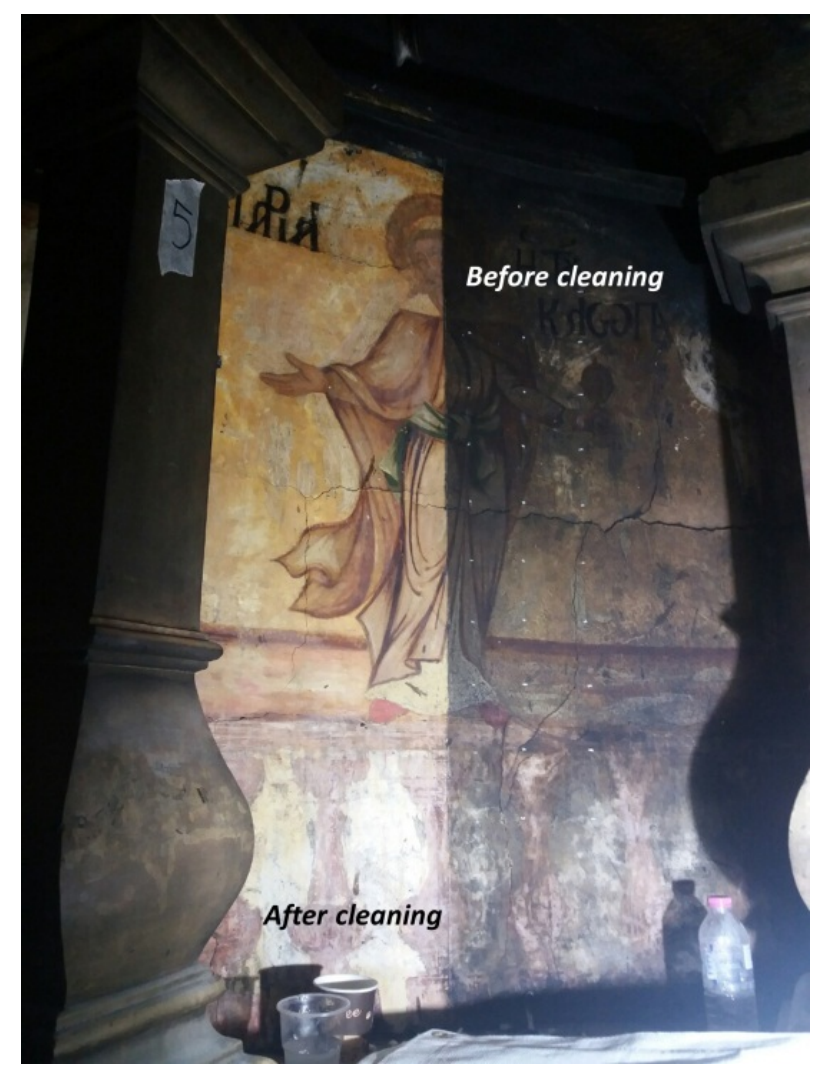

Figure 6. Revealing and conserving the frescoes of the Tomb Chamber

Similar restoration and conservation work was performed at the Onion Dome above the Aedicule which reinstated its structural integrity and revealed decorations (Figure 7). The preserved and revealed mural paintings of the Onion Dome presented repetitive circular patterns that symbolize the holes north and south of the Aedicule's entrance, from which the Holy Light is transmitted by the Greek Orthodox Patriarch of Jerusalem at the liturgy of the noon of the Holy Saturday during Easter Ceremony.

After the structural integrity was assured and the response of the retrofitted structure was validated, the iron frame installed by the British Mandate in 1947 - in order to secure the Aedicule from its prominent deformation - was cut with a plasma cutter, emancipating the Holy Aedicule 
after 70 years (Figure 8).

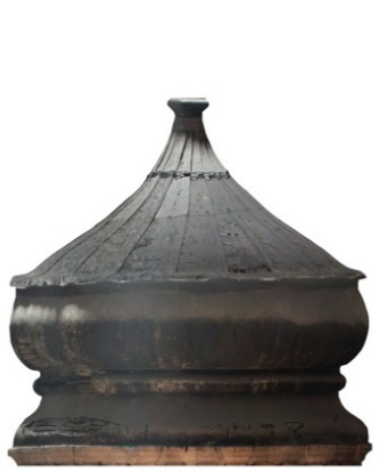

May, 2015

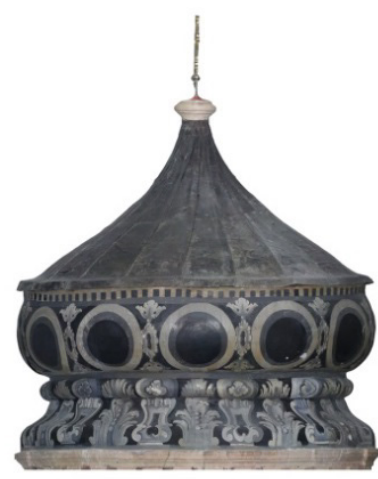

March, 2017

Figure 7. Preserving the mural paintings of the onion dome, symbols of the Holy Aedicules' holes from which the Holy Light is transmitted

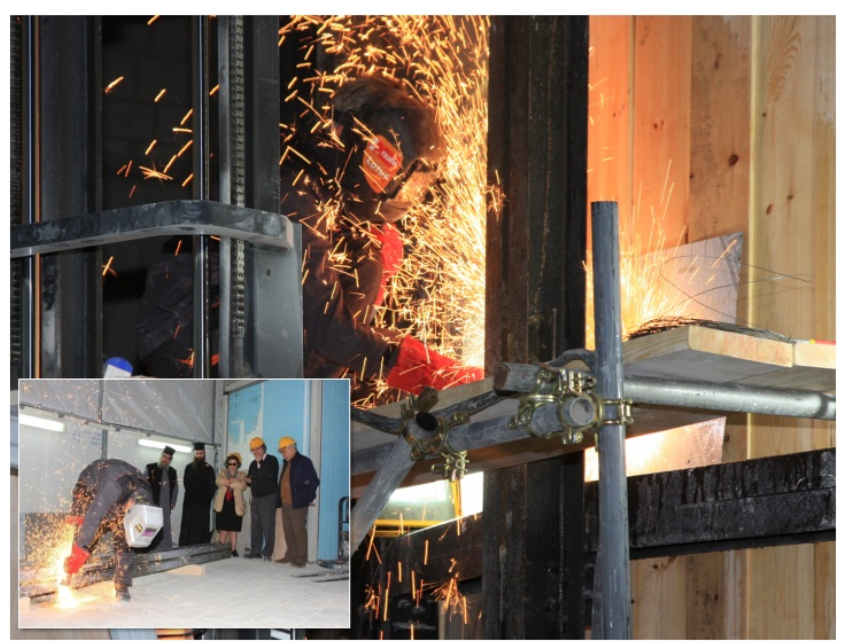

Figure 8. Plasma cutting of the iron beams emancipating the Holy Aedicule 70 years after the British Mandate intervention with the iron frame

The examination of the internal masonry, both through macroscopic investigation and through prospection with non-destructive techniques [12], in combination with characterization of samples of the masonry materials, revealed that Komnenos most probably preserved parts of the earlier Aedicule, embedding them, as well as primary materials within a larger structure in his own construction phase. The preserved parts, at least at the lower height of the current Aedicule, are presumed to have been mainly erected by the Byzantine Emperor Constantine IX, Monomachos, in AD 1042-1048, with interventions from the Crusaders $\left(11^{\text {th }}-12^{\text {th }}\right.$ cent.) (Figure 9) [9]. Furthermore, the roughly reconstructed masonries of the Komnenos phase, as documented in the cases behind the slabs at the western part of the Aedicule, indicate that this construction phase was implemented in conditions of great haste. The documentation of the evolution of the historic construction and restoration phases is of utmost archaeological importance for monument as well as for the city of Jerusalem. The dating of the mortars joining the rock bed

of the Tomb of Christ with the first attached gray marble slab proved that the latest was placed by Constantine the Great $\left(4^{\text {th }}\right.$ cent.). Dating of mortars around the Holy Rock provided evidence to the historic sequence of the Aedicule, since all the restoration eras stemming Byzantine, Crusaders, Renaissance and Komnenos interventions were identified [18].

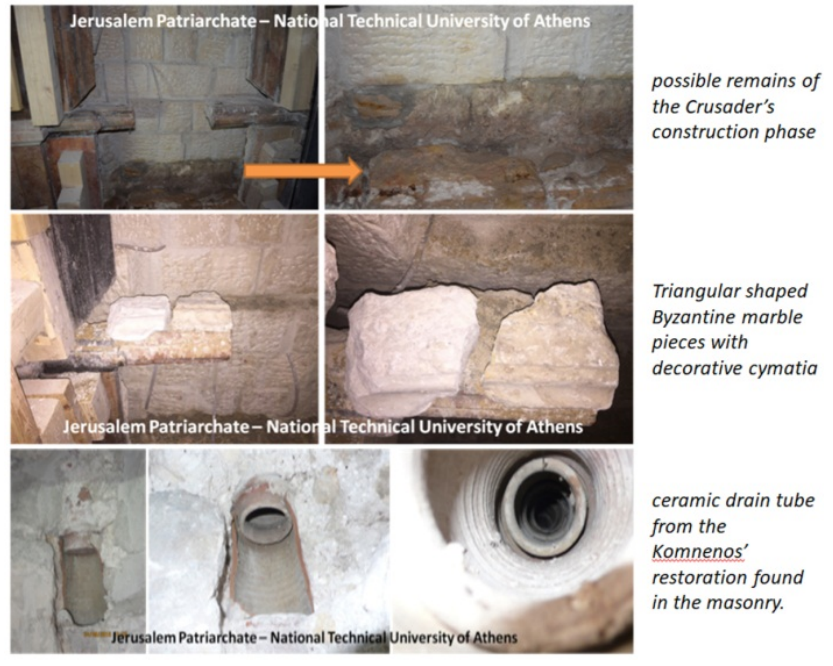

Figure 9. Findings stemming various historic phases within the Aedicule

Here, it is necessary to notice that the archaeological part of the project is still in process, and its scientific results will be announced in due time. It is obvious that in such an intervention although the technical part is completed according to a strict time schedule, archaeology and the processing of the findings, irrespective of their category (architectural or mobile) follows at a later stage, as the processing of the material and the relevant research need the appropriate time in order to be completed. Upon the completion of the preservation of the finds each one is immediately rendered through research articles written from the scientific team to the public, for it is necessary to communicate the results with the latter within the frame of the best practice of public archaeology.

Returning to the prerequisite set that the flow of pilgrims is unobstructed it needs to be noted that the whole history of the Monument apart of its obvious religious significance denotes exactly this point. Throughout the different historical phases of the building it was the focal point of the earliest reason for travelling far - pilgrimage. The human need to visit Holy places formed the first reason for simply travelling without any other practical need (ex. commerce or war). Until today pilgrimage is one of the basic branches of cultural tourism, a realistic way for anyone to see that indeed since antiquity faith can lead literary far in terms of distance [19].

This is acknowledged by all communities and the preservation of such monuments is indeed a 'historical responsibility' as the guardians themselves declare in the agreement. Faith and the right to exercise it in its Holiest 
places are undisputable rights of modern society and a demanding responsibility of the responsible parties. Except today, in the new anthropocentric model that not only the social studies but also the technical studies have acquired, it becomes a responsibility of all sectors of society. Namely, in this case this is embodied in the aforementioned agreement, in the interdisciplinary nature of the project and in the combination of financial resources gathered to support it. The existence of single benefactors is testified since antiquity and public funding and support is also a main characteristic of democratic societies, but in this case the contribution of the World Monuments Fund confirms exactly the global social interest in this category of monuments. The latter in its mission declares that the universality of the narrative of the monuments is a treasure that must be preserved and safeguarded for the future generations. The ideology of the sponsorship is also a matter of interest behind such interventions because not only through the actual funding do such organizations help in the actualization of such projects but also promote the international interest on the artifacts themselves.

Monuments may belong to material culture but such monuments reflect the intellectual and spiritual culture of humanity. Preserving them and bringing forward their religious and social narratives in the present multicultural and socially motivated world, is a step further to focusing on what unites humanity rather than what divides it.

\section{Data Organization for Scientific Support to Decision Making towards Sustainability}

The interdisciplinary NTUA Team using high technology measuring techniques, implemented integrated documentation and monitoring, ensuring scientific support in decision making [20]. The Interdisciplinary Documentation and Monitoring Laboratory was developed, under the supervision of the Chief Scientific Supervisor and was equipped with an array of scientific instruments that covered a wide range of applications for the Holy Aedicule rehabilitation project, categorized as: (i) materials characterization (portable Raman spectrometry system, portable digital microscopy, thermal analysis, etc.), (ii) multispectral diagnostic documentation (UAV with infrared thermal camera, portable spectrophotommetry, digital camera, etc.), (ii) structural analysis (ground penetrating radar, ultrasonic tomography, endoscopic prospection, etc.), (iv) surveying (total station, terrestrial laser scanner, 3D scanner, etc.), (v) structural and environmental monitoring (accelerometers, climate / macro-micro environmental monitoring, etc.). The continuous documentation, diagnosis and pilot applications highly contributed to keep the initial master plan of the scientific team updated.
Through the successful implementation of the project, a need for a five-year monitoring period emerged, in order to assess the thermo-hygric performance and the structural, dynamic and static health of the structure, as well as to ensure verticality by determining any possible deviations from the vertical or horizontal plane. Furthermore, the effect that the high flow of pilgrims has on the structure will thus be monitored. For an integrated documentation and the continuous monitoring of the works and research evolution, an innovative Information System, with Data Integration in $5 \mathrm{D}$, is developed that can serve data archiving, retrieval and analysis. In particular, based upon the geometric documentation of the monument, an optimized spatial database for storing and querying data that represent objects defined in a geometric space, will not only allow the spatial and time-data registration, assigned to multi-layer deformations, but will also enable optimal data querying and single-click geo-referenced data and files uploading (interlinking with phases \& layers). Innovative features also involve walk-through navigation, cross-discipline data analytics for automated identification of threats and triggering of alerts. Thus, various researchers from different disciplines are able to register their data directly to the location and/or area where the measurements were made. This platform is the cornerstone for data management, knowledge acquisition and information sharing [21].

Through the successful rehabilitation process, the Holy Rock was preserved, consolidated and protected. The initial declined state of preservation of the Holy Rock would have led to its complete disaggregation within the next few decades, if the implemented conservation actions had not been applied. The Holy Rock would have been even more susceptible to continuous moisture uptake through capillary rise, as well as to the impact of thermohygric cycles and salt phenomena; this has now been reversed to a great extent, ensuring its longevity, towards sustainability.

\section{Integrated Project Governance and Social Accessibility in the Preservation of Values}

Besides the considerable engineering and scientific challenges involved, the rehabilitation of the Holy Aedicule, was not only a structural issue or choice, but a demand to preserve the values of the monument [22]. The Holy Rock is the initial structure, the core of the Holy Aedicule at the center of the Holy Sepulchre and the symbol of Christianity. It stands both as a physical entity and as a symbol and provides the archetypal meaning to the "structure" Aedicule. The funerary monument, which was erected after the destruction of the Holy Rock in order to signify and enhance it, represents a religious, historical and 
cultural monument of a highest significance. Through the implementation of this project, involving the integrated governance with the responsibility of the three Christian communities and the scientific supervision and monitoring of the NTUA interdisciplinary team, the Holy Aedicule becomes an international focus of innovative applications, research and education, in addition to its religious, cultural and political significance for the three religions and the two peoples of Jerusalem.

The key points are the intersection of the different disciplines and the multi- interface interactions [23, 24] between the scientific teams, the working groups, the Technical Bureau of the Patriarchate and the three Christian communities, all under the authority of His Beatitude, Theophilos III. The Common Agreement (Figure 1) respecting the Status Quo of the three Christian communities responsible for the Holy Tomb provided the statutory framework for the implementation of the project, which was initiated, became possible and was executed under the integrated governance of the project (Figure 10), comprised by the Project Owners Committee, the Steering Committee, adjoining the scientific and the technical directors of the project. The NTUA Interdisciplinary Team (Figure 11) played a major role in all phases of the study and the rehabilitation project.

The three Christian communities, entrusted Science at an unprecedented rate, and became the centripetal force as it reunited more than seventy, academics, workers, conservators, researchers, practitioners, heritage professionals, policymakers, cooperating in order to solve a common, pressing problem, the one of the sustainable preservation of the Aedicule [25]. This Transdisciplinary context $[26,27]$, had an impact on academic production itself, shifting more and more from the technical/ scientific rationality towards an epistemic culture, which, ultimately, lead different disciplines not to try to "establish" their academic discourse, or allow a distinct discipline to have an epistemic privilege over the other [28]. The opening to Transdisciplinarity with the scientific "world" of History and Archaeology was established [29-31] at public dialogue with the Israel Antiquities Authority, the International Conference on Art and Archaeology and the School of Archaeology at the University of Oxford.

Contributions from entities and persons from all over the world secured the project's funding, with the generous Mica Ertegun's donation through World Monuments Fund prevailing. The latter institution, following the completion of the project, was responsible to proceed into an evaluation control in order to secure that the project would be effective in achieving the intended objectives. The aforementioned assessment apart from successful was also quantitative and qualitative inclined.

However, it is essential to acknowledge that the cultural impact of the project, a difficult task to assess [32] before or after the implementation, started to become clearer only upon the completion ceremony and after. The synchronized presence [33] of the religious and political authorities of all ranks, along with the representatives of public and social institutions, deriving from five continents, and the pilgrims of different nations and faith (Figure 12), reflected in the most immediate way, that the project of the Rehabilitation of the Holy Aedicule embodies the values of intercultural, interreligious communication and mutual understanding, between different countries and different people with different religious \& theological backgrounds.

The Media acted as a catalyst to disseminate the values of the monument, especially during the opening of the Holy Tomb developing thus a range of cultural and educational perspectives and furthermore offering new insights into the project [34]. The presence of the media was not only helpful towards the undertaking of the project when it was challenged by adversities and/or impasses, but rather and most importantly, enhanced its social accessibility, in terms of making the monument and its heritage, i.e. the values of Resurrection (Anastasis), more accessible to the general public and to a wider audience all over the world.

The enhancement of the social accessibility from distance combined with a 3-D digital experience of the monument, based on the Rehabilitation of the Holly Aedicule project has been the aim of the exhibition "Tomb of Christ: The Church of the Holy Sepulchre Experience", which was organized at the Museum of National Geographic, in Washington DC, USA, by National Geographic and NTUA, in Nov. 15, 2017- Aug. 15, 2018. This kind of experience brings even more forward the issue of accessibility since it can give the opportunity to those have not made yet the journey of the pilgrimage to get a glimpse of what will be revealed to them in the Holy Sepulchre. It must be noted though that technological means of approaching the monument are accessory to the experience of the monument itself and they cannot in any means replace the feeling of the actual visitor. Within 2018, the exhibition will be hosted in the Byzantine and Christian Museum of Athens, while other Museums of the world are expressing their interest as well.

The research developed for the Rehabilitation of the Holy Aedicule by NTUA was implemented and completed with Innovation, marking future trends in the protection of monument (as declared in Brussels 14.03.2017 by the representatives of the DG: Research \& Development, Education \& Culture, ICT/Connect) and in addition in "Digital solutions and multi-layer data innovations in the rehabilitation of the Holy Aedicule of the Holy Sepulchre in Jerusalem" 20.03.2018, in Innovation and Cultural Heritage High-level Horizon 2020 conference of The European Year of Cultural Heritage, Royal Museum of Arts and History, Brussels. Further research is currently taking place by processing the scientific data collected in the Integrated Information System Platform (NTUA) and of the material examined in the scientific laboratories. To 
this extend an archaeometric study of the samples taken from the covering plaque has been published recently [18] while the archaeological and historical disciplinary treatment is under discussion between NTUA and the School of Archaeology, University of Oxford.

The rehabilitation of the Holy Aedicule was successfully completed by the NTUA Team and delivered to the responsible parties, thus the Christian Communities, Guardians of the Holy Tomb. However, during the works, it was revealed that the Holy Aedicule is located above a complex underground environment (a cluster of underground cisterns, and natural and manmade underground voids and effective archaeological excavations) which poses risks and hazards that can threaten the sustainability of the rehabilitated structure. To address these issues, the study proposes three years underground works, and installing a proper drainage water system around the perimeter of the Rotunda [9].

\section{INTEGRATED GOVERNANCE OF THE PROJECT}

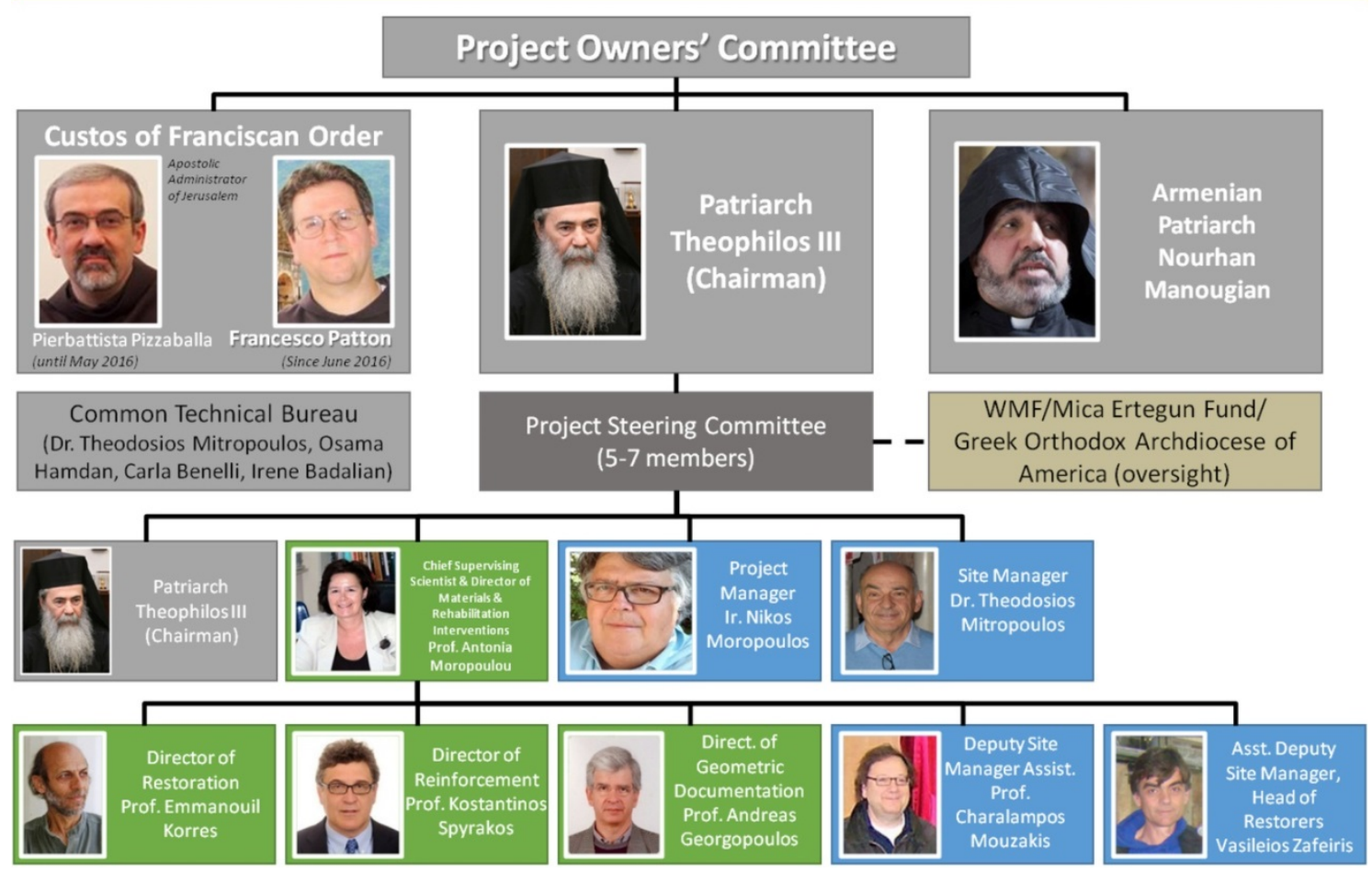

Figure 10. Integrated governance of the project 
"Protection of Monuments" contributing to the Project:

Chief Scientific Responsible: Prof. A. Moropoulou

Scientific Responsibles of the Interdisciplinary Team: Prof. A. Moropoulou, Prof. Emm. Korres, Prof. A. Georgopoulos, Prof. C. Spyrakos, Asst. Prof. Ch. Mouzakis

NTUA School of Civil Engineering: Prof. C. Spyrakos, Asst. Prof. Ch. Mouzakis, Prof. Emeritus P. Marinos, Assoc. Prof. M. Kavvadas, EDIP S. Asimakopoulos, EDIP L. Karapitta, Dr. Ch. Maniatakis, PhD Can. L. Panoutsopoulou

NTUA School of Architecture: Prof. Emeritus Emm. Korres, V. Chasapis Arch

NTUA School of Chemical Engineering: Prof. A. Moropoulou, Prof. Emeritus G. Batis, Asst. Prof. A. Bakolas, EDIP E. T. Delegou, EDIP M. Karoglou, EDIP K. C. Lampropoulos, EDIP P. Moundoulast, PhD. Cand. Emm. Alexakis, PhD. Cand. M. Apostolopoulou, PhD Cand. I. Ntoutsi, PhD Cand. E. Tsilimantou, Dr. A. Zacharopoulou, N. Galanaki, M. Kalofonou. Secretarial and administrative support A. C. Lampropoulou. Finance and administrative support G. Skoulaki. Technical support, I. Mountrichas.

School of Rural and Surveying Engineering: Prof. A. Georgopoulos, Prof. Ch. loannidis, Assoc. Prof. E. Lambrou, Assoc. Prof. G. Pantazis, Asst Prof. A. Doulamis, ETEP S. Soile, ETEP S. Tapeinaki, ETEP R. Chliverou, Phd. Cand. P. Agrafiotis, PhD Cand. E. Stathopoulou, L. Kotoula, F. Bourexis, A. Papadaki, N. Tsonakas, P. Nikolakakou, M. Skamantzari

The Interdisciplinary NTUA team has cooperated with other Schools, Laboratories and scientific collaborators: Prof. S. Kourkoulis and PhD. Cand. E. Passiou from NTUA School of Applied Mathematics and Physical Science, Sector of Mechanics, Mech. Eng. M. Agapakis, A. Fragkiadoulakis, S. Theocharis and Chem. Eng. I. Agapakis

NTUA Inter-Departmental Postgraduate Program "Protection of monuments, sites and complexes", Direction Conservation Interventions: Techniques and Materials graduate students D. Giannakopoulos, A. Zargli, A. Kolaiti, E. Koukouras, M. Kroustallaki have conducted Master Theses interconnected to the project

The Interdisciplinary NTUA team has cooperated with: University of Piraeus, University of Peloponnese, Agricultural University of Athens, Institute of Geology \& Mineral Exploration (I.G.M.E.), Athens Water Supply and Sewerage Company (EYDAPS.A.)

- Specifically, with Assist. Prof. D. Kyriazis (Electrical Engineer) from the University of Piraeus, Assoc. Prof. N. Zacharias from the University of Peloponnese, EDIP A. Tsagkarakis from the Agricultural University of Athens, G. Economou, G. Papatrechas from the Institute of Geology \& Mineral Exploration (I.G.M.E.) and A. Aggelopoulos, E. Karampelas and D. Tamvakeras from EYDAP S.A., P. Sotiropoulos (TerraMarine)

- In the post-project period, the NTUA Research Fellows Dr. A. Kioussi, Archaeologist, and C. Farmakidi, Archaeologist

Project Manager: N. Moropoulos, Civil Engineer - Informatics

Construction Site Manager: Dr. Th. Mitropoulos, Architect of the Common Technical Bureau

Deputy Construction Site Manager: Asst. Prof. Ch. Mouzakis

Assistant Deputy Construction Site Manager and Head of the Restorers: V. Zafeiris, Civil Engineer

Restorers and Masons Team: I. Andritsopoulos, C. Theodorakis, A. Karydis, P. Chaloftis, G. Anastasiadis, Senior Marble Mason, G. Palamaris, Marble Mason

Conservators Team: Th. Mavridis, MSc Conservator, Employee of the Greek Ministry of Culture, M. Troullinos, Conservator, K. Karathanou, MSc Archaeologist - Conservator, Employee of the Greek Ministry of Culture, Am. Troullinou, Conservator, Ar. Troullinou, Conservator

Figure 11. NTUA Team for the rehabilitation of the Holy Aedicule of the Holy Sepulchre 


\section{Conclusions}

In practice the protection of Cultural Heritage monuments is interconnected with "Keeping Heritage Alive". This process is a substantial aspect of Monuments' Protection and must be connected with the use or re-use of the monument, as well as by helping Society through active participation to "understand" the monument, its needs and values, leading to the acceptance of the interventions. The case of the rehabilitation of the Holy Aedicule of the Holy Sepulchre proves the bilateral importance of social accessibility in the protection of monuments, as demonstrated by mutual development of the dynamics of the two processes:

- The rehabilitation project was designed in order to be accessible to the pilgrims as well as allow the religious function of the Christian communities. This is the first time that these have been accomplished at this scale.

- The progress of the rehabilitation project was decisively combined with the communication of the project to all Humanity, from the moment the Holy Tomb opened and until the Holy Aedicule was delivered rehabilitated to the Christian Communities. Further than that and since communities form the foundation of society and form the sense of 'belonging' in a common world, the Holy Aedicule, as indicated also in the common agreement is there for anyone seeking 'spiritual renewal', a notion innate to human existence and inherited through culture in all civilizations. Monuments as the discussed one therefore are at the focus of the essence of humanity itself irrespective of the strict canonistic religious identity.

- The flow of pilgrimage more than tripled after the completion of the rehabilitation project, indicating that the improved state of the monument, as well as the achievements of the rehabilitation by preserving, by revealing and by emitting the values of the monument, led to an enhanced dialogue of the monument with Humanity, bridging their connection. This is to prove that interdisciplinary projects apart from bringing experts together not only enhance social accessibility by increasing the interest of multiple social groups, but also stimulate activity around the monuments themselves.

- The post-project interest, as well as the transmittance and dissemination of the values of the monument, along with the representation of the project through public speeches and presentations, scientific publications, exhibitions etc., developed a new dynamic between the common opinion and the monument. The project was feasible through the historic decision of the three Christian Communities to implement the NTUA study with executive authorization to the Chief Scientific Supervisor.

Today, by informing and acquainting the public with issues of monitoring and the effects of the environmental factors, a public opinion emerges which demands that the project ensures sustainability throughout the centuries. The interdisciplinary NTUA team, the innovative knowhow applied, the scientific dialogue employed, act as a catalyst for the development of this interactive dynamics between the Monument and Humanity. Through this study, a conversation is initiated regarding the idiosyncratic interrelation between social accessibility and monument protection, the preservation of values being the critical line. The core of the rehabilitation was carried out in a context of scientific state-of-the-art and innovative engineering applications aiming to highlight that the Holy Aedicule can also re-emerge as an emblematic center of innovative applications, research and Education. The preservation of monument heritage being one of the basic pillars of sustainability brings forward the multiplicity and cultural variety that our present world is based on. We may all come from different backgrounds but preserving the past is the way to plan the future through the active involvement of all communities, as in the case of this Monument [35].

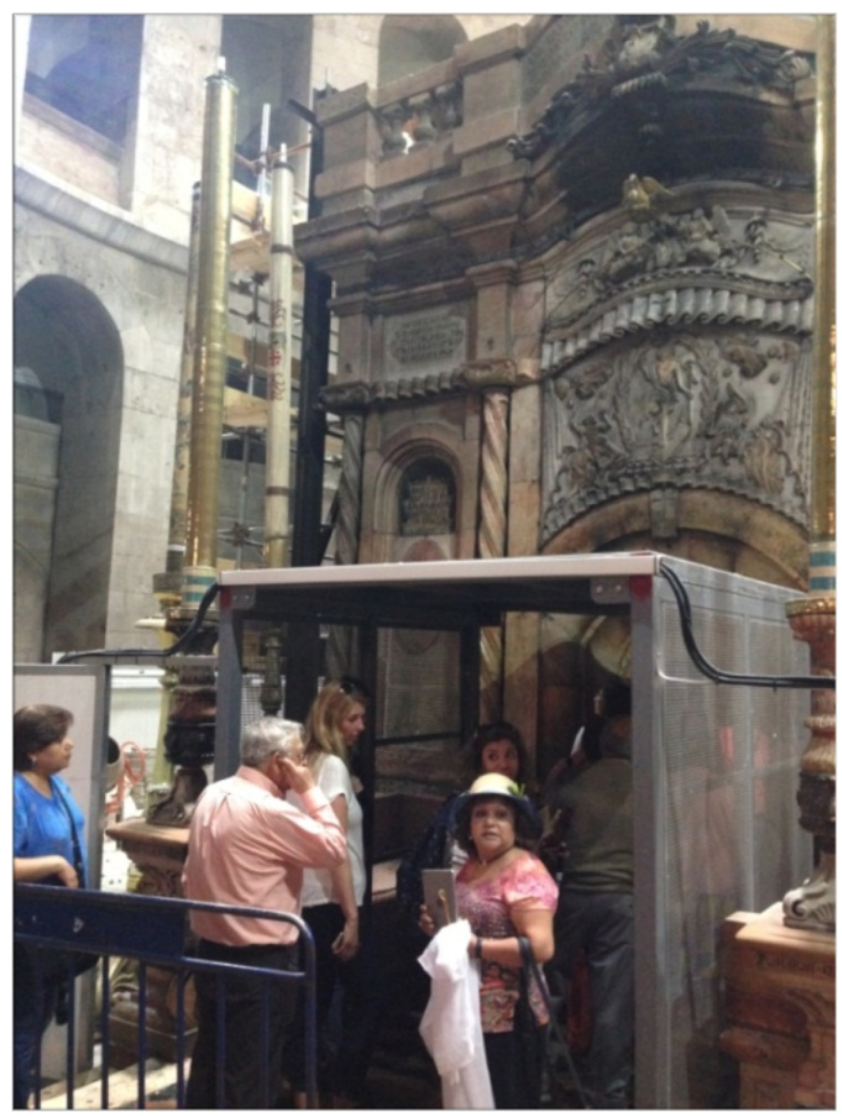

Figure 12. Pilgrims of different nations and faith 


\section{Acknowledgements}

The study and the rehabilitation project of the Holy Aedicule became possible and were executed under the governance of His Beatitude Patriarch of Jerusalem, Theophilos III. The Common Agreement of the Status Quo Christian Communities provided the statutory framework for the execution of the project; His Paternity the Custos of the Holy Land, Archbishop Pierbattista Pizzaballa (until May 2016 - now the Apostolic Administrator of the Latin Patriarchate of Jerusalem), Fr. Francesco Patton (from June 2016), and His Beatitude the Armenian Patriarch of Jerusalem, Nourhan Manougian, authorized His Beatitude the Patriarch of Jerusalem, Theophilos III, and NTUA to perform this research and the project. Contributions from all over the world secured the project's funding. It is worth noting Mica Ertegun's and Jack Shear's donations through WMF, Aegean Airlines et al. The interdisciplinary NTUA team for the Protection of Monuments: Em. Korres, A. Georgopoulos, A. Moropoulou, C. Spyrakos, Ch. Mouzakis, were responsible for the rehabilitation project and A. Moropoulou, as Chief Scientific Supervisor, was responsible for its scientific supervision.

\section{REFERENCES}

[1] M. Biddle The Tomb of Christ. Gloucestershire England, Sutton, 1999.

[2] M. Biddle, G. Avni, J. Seligman, T. Winter. The Church of the Holy Sepulchre. New York, N.Y.: Rizzoli in cooperation with Israel Antiquities Authority, 2000 Publisher: Rizzoli; 1 st edition (July 7, 2000)

[3] J. Patrich. An Overview on the Archaeological Work in the Church of the Holy Sepulchre. In: The Archaeology andHistory of the Church of the Redeemer and the Muristan in Jerusalem, edited by D. Vieweger and S. Gibson. Archaeopress Publ. Ltd, Oxford (2016) 139-161

[4] T. Mitropoulos. The Church of Holy Sepulchre - The Work of Kalfas Komnenos. European Centre of for Byzantine and Post-Byzantine Monuments; 2009 (in Greek)

[5] C. O.P. Coüasnon. The Church of the Holy Sepulchre in Jerusalem. The Schweich Lectures of the British Academy 1972. Oxford University Press; 1974

[6] R. Ousterhout. Architecture as Relic and the Construction of Sanctity: The Stones of the Holy Sepulchre. Journal of the Society of Architectural Historians. 2003; 62 (6): 4-23

[7] Integrated diagnostic research project and strategic planning for materials, interventions conservation and rehabilitation of the Holy Edicule of the Holy Sepulchre in the Holy Church of the Resurrection in Jerusalem: Booklet on the study by A. Moropoulou, E. Korres, A. Georgopoulos, C. Spyrakos, (2016) ISBN 978-618-82612-0-4

[8] A. Moropoulou, A. Georgopoulos, M. Korres, A. Bakolas, K.
Labropoulos, P. Agrafiotis, E.T. Delegou, $\uparrow$ P. Moundoulas, M. Apostolopoulou, E. Lambrou, G. Pantazis, L. Kotoula, A. Papadaki, E. Alexakis. Five Dimentional (5D) Modeling of the Holy Aedicule of the Church of the Holy Sepulchre through an innovative and interdisciplinary approach. In : Mixed Reality and Gamification for Cultural Heritage, Springer International Publishing, edited by M. Ioannides, N. Magnenat-Thalmann, G. Papagiannakis (2017) 247-270

[9] Presentation on the completion of the Holy Sepulcher's Holy Aedicule Rehabilitation. Booklet on the completion by A. Moropoulou, ISBN 978-618-82196-4-9

[10] A. Moropoulou, E. Korres, A. Georgopoulos, C. Spyrakos, C.H. Mouzakis, K.C. Lampropoulos, M. Apostolopoulou, E.T. Delegou, Em. Alexakis, "The rehabilitation of the Holy Aedicule", Scienza e Beni Culturali XXXIII, Le Nuove Frontiere del Restauro: Trasferimenti, Contaminazioni, Ibridazioni, Arcadia Ricerche Editore (2017) 1-16.

[11] A. Moropoulou, E. Korres, A. Georgopoulos, C. Spyrakos, Ch. Mouzakis, E. Lambrou, G. Pantazis, M. Kavvadas, P. Marinos, N. Moropoulos, V. Zafeiris, K. Lampropoulos, M. Apostolopoulou, Ch. Maniatakis, M. Agapakis, J. Agapakis, A. Fragkiadoulakis. Faithful Rehabilitation. History, culture, religion, and engineering all intertwined in a recent project in Jerusalem to rehabilitate and strengthen the site believed to be the tomb of Jesus of Nazareth. Modern methods, including 3-D laser scanning, Non Destructive Techniques and ground-penetrating radar, combined with careful documentation and design, revealed the secrets of how to help preserve and sustain the ancient site for future generations. Journal of the American Society of Civil Engineers [November 2017]

[12] K. Lampropoulos, A. Moropoulou, M. Korres, "Ground penetrating radar prospection of the construction phases of the Holy Aedicula of the Church of the Holy Sepulchre in correlation with architectural analysis", Construction and Building Materials 155 (2017) 307-322

[13] P. Agrafiotis, K. Lampropoulos, A. Georgopoulos, A., Moropoulou, 3D Modelling the Invisible using Ground Penetrating Radar. in: D. Aguilera, A. Georgopoulos, T. Kersten, F. Remondino, and E. Stathopoulou (Eds.), TC II \& CIPA 3D Virtual Reconstruction and Visualization of Complex Architectures, 1-3 March 2017, Nafplio, Greece. Int. Arch. Photogramm. Remote Sens. Spatial Inf. Sci. 2017; XLII-2-W3: 33-37

[14] M. Apostolopoulou, E. Aggelakopoulou, A. Bakolas, A. Moropoulou (In press, 2017), "Compatible Mortars for the Sustainable Conservation of Stone in Masonries", In Majid Hosseini and Ioannis Karapanagiotis (Eds): "Advanced Materials for the Conservation of Stone", Volume 1, Springer International Publishing

[15] EAC2 conference (Second International RILEM/COST Conference On Early Age Cracking and Serviceability in Cement-based Materials and Structures [Brussels, Belgium, 12-14/9/2017]: "NDT assessment of the rehabilitation of the Holy Aedicule of the Holy Sepulchre concerning the implementation of compatible and performing restoration mortars", by M. Apostolopoulou, E.T. Delegou, K.C. Lampropoulos, E. Alexakis, A. Moropoulou

[16] A. Georgopoulos, E. Lambrou, G. Pantazis, P. Agrafiotis, A. Papadaki, L. Kotoula, K. Lampropoulos, E. Delegou, M. Apostolopoulou, M. Alexakis, A. Moropoulou, «Merging 
geometric documentation with materials characterization and analysis of the history of the Holy Aedicule in the Church of the Holy Sepulchre in Jerusalem» Geomatics and Restoration : Conservation of Cultural Heritage in the Digital Era, The International Archives of the Photogrammetry, Remote Sensing and Spatial Information Sciences, edited by G. Tucci, V. Bonora, Volume XLII-5/W1 (2017) 487-494

[17] A. Moropoulou, E.T. Delegou, I. Ntoutsi, M. Apostolopoulou. Analytical and Technological Investigation of the Paintings and other Decorative Elements of the Holy Aedicule of the Holy Selpuchre in Jerusalem. TECHNART - Non-destructive and microanalytical techniques in Art and Cultural Heritage [Bilbao, Portugal, 2-6/5/2017]

[18] A. Moropoulou, N. Zacharias, E. Delegou, M. Apostolopoulou, E. Palamara, A. Kolaiti. OSL Mortar Dating to Elucidate the Construction History of the Tomb Chamber of the Holy Aedicule of the Holy Sepulchre in Jerusalem. Journal of Archaeological Science: Reports [accepted]

[19] OECD Organisation for Economic co-operation and Development, The Impact of Culture on Tourism, Paris, $2009,25$.

[20] EAC2 conference (Second International RILEM/COST Conference On Early Age Cracking and Serviceability in Cement-based Materials and Structures [Brussels, Belgium, 12-14/9/2017]: "NDT assessment of the rehabilitation of the Holy Aedicule of the Holy Sepulchre", keynote presentation by Prof. A. Moropoulou

[21] E. Alexakis, E. Kapassa, M. Touloupou, D. Kyriazis, A. Georgopoulos, A. Moropoulou, "Computer-Aided Innovative Methodology for Management and Personalized Representation of Big Data in Cultural Heritage”. The 9th International Multi-Conference on Complexity, Informatics and Cybernetics: IMCIC 2018, March 13 - 16, 2018, Orlando, Florida. (Forthcoming)

[22] K. V. Mulcahy. Cultural policy: Definitions and theoretical approaches, The Journal of Arts Management, Law and Society, 35 (4): 319-330, 2006.

[23] M. M. Kaiser. Leading Roles. 50 Questions Every Arts Board Should Ask. Hanover and London: Brandeis University Press. 2010.

[24] W.A. Jones. Variation among academic disciplines: An update on analytical frameworks and research, The Journal of Professoriate, 6 (1), 9-27, 2011.

\footnotetext{
${ }^{\mathrm{i}}$ a collective work presented by Professor Antonia Moropoulou
}

[25] S. Rizvi. Multidisciplinary Approaches to Educational Research: Case Studies from Europe and the Developing World. New York, NY: Routledge. 2012

[26] M. Gibbons, C. Limoges, H. Nowotny, S. Schwartzman, P. Scott, \& M. Trow. The New Production of Knowledge: The Dynamics of Science and Research in Contemporary Societies, Thousand Oaks, CA: Sage Publications, 1994, 192.

[27] A. Karlqvist. Going beyond disciplines the meanings of interdisciplinarity, Policy Sciences, 32: 379-383, 1999.

[28] J. Paquette, and E. Redaelli. Arts Management and Cultural Policy Research. Palgrave Macmillan, 2015.

[29] 10th Annual Conference on "New studies in the archaeology of Jerusalem" [Jerusalem, 26-28/10/16, joint collaboration of the Israel Antiquities Authority, Tel Aviv University and The Hebrew University of Jerusalem]: Invited presentation: "Sustainable rehabilitation of the Holy Sepulchre: Interdisciplinary scientific study and monitoring - Scientific integrated governance of the project", a collective work presented by Prof. A. Moropoulou

[30] 2nd International Conference on Art and Archaeology [Jerusalem, 11-14/12/2016]: Invited lecture: "Interdisciplinary planning and scientific support in the field of rehabilitation of the Holy Aedicule of the Holy Sepulchre", a collective work presented by Prof. A. Moropoulou

[31] University of Oxford School of Archaeology: Fifth Anniversary of the Mica and Ahmet Ertegun Graduate Scholarship Programme in the Humanities [Oxford, 23/10/2017]: "The Rehabilitation of the Holy Aedicule of the Holy Sepulcher", by Prof. A. Moropoulou

[32] C. Gray. Analysing cultural policy: Incorrigibly plural or ontologically incompatible? International Journal of Cultural Policy, 16 (2): 215-230, 2010.

[33] C. Madden. Indicators for arts and cultural policy: A global perspective, Cultural Trends, 14 (3): 217-247, 2005.

[34] P. Schlesinger. Expertise, the academy and the governance of cultural policy, Media, Culture and Society, 35 (1): 27-35, 2013.

[35] J. Hawkes. The Fourth Pillar of Sustainability: Culture's Essential Role in Public Planning, Common Ground Publishing, Australia, 2001, 28-31. 